Working Paper n. 02 - 2014

\title{
DOES THE HOME ADVANTAGE DEPEND ON CROWD SUPPORT? EVIDENCE FROM SAME- STADIUM DERBIES
}

Michela Ponzo

Dipartimento di Scienze Economiche e Statistica

Università degli Studi di Napoli Federico II Complesso Universitario di Monte Sant'Angelo

Via Cintia, 21 - 80126 - Napoli

Tel.: +39081675036

e-mail: michela.ponzo@unina.it
Vincenzo Scoppa

Dipartimento di Economia,

Statistica e Finanza

Università della Calabria

Ponte Pietro Bucci, Cubo 1/C

Tel.: +390984 492464

Fax: +390984 492421

e-mail:v.scoppa@unical.it

\section{Marzo 2014}

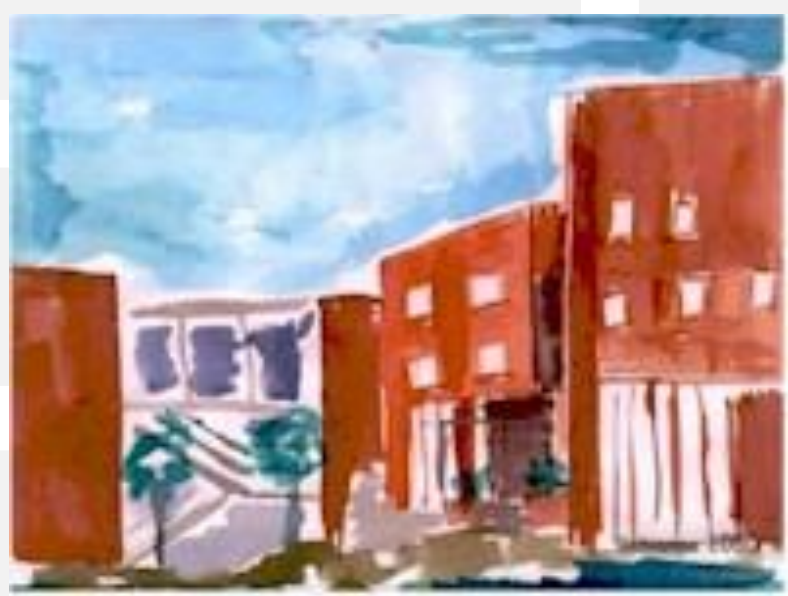




\title{
Does the Home Advantage Depend on Crowd Support? Evidence from Same-Stadium Derbies
}

\author{
Michela Ponzo, Vincenzo Scoppa*
}

This version: 13 March 2014

\begin{abstract}
We investigate to what extent crowd support contributes to the home advantage in soccer, disentangling this effect from other mechanisms such as players' familiarity with the stadium and travel fatigue. To evaluate the relevance of crowd support in determining home advantage we analyze same-stadium derbies (matches among teams that share the same stadium) in which teams enjoy different levels of support from the crowd - the home team has many more supporters, mainly because of season ticket holders - while teams do not differ in terms of travel fatigue or familiarity with the stadium. Our estimation results suggest the existence of a sizable crowd support's effect on the home advantage generated both through the influence on referee's decisions and through the encouragement of players' performance.
\end{abstract}

JEL classification: D89; L83; D81

Keywords: Soccer; Home Advantage; Crowd Support; Social Pressure; Team Performance; Attendance; Travel Fatigue; Stadium Familiarity; Referee Home Bias

\section{Introduction}

Home advantage - the tendency for the home team to win more often than the visiting team - is one of the best documented phenomenon in soccer and in sports in general (for surveys, see Courneya and Carron, 1992; Nevill and Holder, 1999; Pollard and Pollard, 2005). However, the determinants of the home advantage have been difficult to identify. Three main factors have been recognized and empirically analyzed in the literature: crowd support; familiarity with the stadium; travel fatigue. ${ }^{1}$

As regards the first mechanism, the home team typically receives a stronger support from the crowd, which tend to stimulate players' effort and energy and lead them to perform better. In addition, the noise and the reactions of the crowd tend to subconsciously influence the referee's decisions in favor of the home team.

\footnotetext{
* M. Ponzo: Department of Economics and Statistics, University of Naples Federico II, Napoli, Italy. E-mail: michela.ponzo@unina.it.

V. Scoppa: Department of Economics, Statistics and Finance, University of Calabria, and IZA (Bonn): Address: Dipartimento di Economia, Statistica e Finanza, Università della Calabria, Via Ponte Bucci, 87036 Arcavacata di Rende (CS), Italy. E-mail: v.scoppa@unical.it.

We would like to thank Vincenzo Carrieri, Maria De Paola, Sabrina Giordano, Andrea Ottolina, Pier Francesco Perri for useful comments and suggestions.

${ }^{1}$ A fourth factor - considered for other sports - is represented by some specific rules of sport that tend to favor the home team. However, this asymmetry does not apply to soccer: rules are identical for the home and the visiting team (Pollard, 2006)
} 
To evaluate the strength of this mechanism, some studies have examined the association between crowd size and team performance. The evidence is somewhat mixed. Pollard and Pollard (2005) show no difference in the magnitude of the home advantage despite considerable differences in crowd size between the first and second division in the leagues of Germany, England, France, Spain and Italy. Similarly, Pollard (1986) and Clarke and Norman (1995) find that the home advantage varies little over the four divisions in England. Using a different approach, Salminen (1993) and Strauss (2002) have shown that spectators' support (for example, cheering) for the home team is not related to home team success.

In contrast to these findings, Agnew and Carron (1994) found a positive association between crowd density and the home advantage. Moreover, Pollard (2006) argues that the drop in the home advantage during the 1990s in England could be due to mandatory requirement for all-seater accomodation in stadiums implying less dense and more expensive seating, leading to less crowd support.

More clear evidence exists on the home bias of officials' decisions, which represents an indirect effect of the crowd operating through the referee. Many studies have shown that referees can be subconsciously influenced by the noise of a large crowd in the stadium and react by favoring the home team, awarding more penalties and less disciplinary sanctions to the home team or conceding more injury time to it when is behind (Nevill et al. 2002; Garicano et al., 2005; Dohmen, 2008; Sutter and Kocher, 2004; Scoppa, 2008; Dawson and Dobson, 2010; Page and Page, 2010).

The second cause of the home advantage originates from the familiarity with the stadium: home team players are generally more familiar with their own venue in terms of dimensions, playing surfaces, and other physical features, and exhibit greater confidence when playing in a more familiar environment. The existing evidence shows that teams playing on unusual larger or smaller playing surfaces or on artificial surfaces (rather than on grass) enjoy an additional advantage compared with other teams whose home grounds are more standard suggesting the possible advantage gained by the home team on these pitches (Clarke and Norman, 1995; Barnett and Hilditch, 1993). Furthermore, the home advantage seems to be reduced when a team moves to a new stadium probably due to the loss of familiarity with home playing conditions (Pollard, 2002). ${ }^{2}$ In contrast, Loughead, Carron, Bray and Kim (2003) found that the home advantage did not change after teams relocate to a new venue.

Finally, researchers have analyzed the role of travel fatigue in the home advantage, arising from the fact that the away team has the disadvantage of traveling and suffer from disruption of the preparation. The evidence on this aspect is quite robust. Oberhofer, Philippovich and Winner (2010) analyze if team performance in soccer is related to the distance from the home location and the away playing venue. They use data from German Football Premier League and show that team performance (measured in terms of scored and conceded goals) decreases with the distance to the playing venue. Similar findings are also confirmed in a study of the English Premier League matches (Clarke and Norman, 1995) showing that the

\footnotetext{
${ }^{2}$ A recent study by Neave and Wolfson (2003) refers also to a psychological trait as "territoriality", that is "the protective response to the invasion of one's perceived territory" and show that football players experience higher testosterone concentrations at home matches than away which increases their aggression and allows them to perform better.
} 
home advantage increases with the distance travelled by away teams. In an analysis of the Australian League, Goumas (2014) finds evidence that in soccer competitions where time zones are crossed, travel effects, such as jet lag, may play an even greater role in home advantage than crowd support. In the same vein, Nichols (2014) studies US National Football League matches and finds that visiting teams traveling from longer distances (and in particular from west to east, crossing at least one time zone) appear to experience poorer performance.

Some authors (Brown et al., 2002; Pollard, 1986) have suggested that the higher home advantage in European and international competitions could be related to the larger distances travelled by away teams whose players are tired after long travelling. Furthermore, the reduction of the home advantage in recent times could be due to the fact that travel has become easier and more comfortable during this period.

All in all, although the evidence on the existence of the home advantage is solid, the mechanisms through which it operates are still unclear and in particular the empirical evidence is not conclusive on the relative relevance of crowd support, travel fatigue and stadium familiarity (Courneya \& Carron, 1992; Pollard and Pollard, 2005).

The purpose of the paper is an attempt to evaluate the relative weight of these mechanisms in soccer. Specifically, in order to identify the role of crowd support - as distinguished from other factors - in this paper we exploit the fact that a number of teams (from the large cities of Rome, Milan, Turin, Genoa and Verona) in the Italian "Serie A" share the same stadium: when playing one against the other - in so-called "same-stadium derbies" - players of both teams are familiar with the pitch and facilities and, in addition, they suffer no travel fatigue and no interruption of preparation.

The only difference in a derby between, for example, Milan and Inter is that when Milan is the home team, because of season ticket holders and reservations for home team's supporters in the sale of tickets, only a sector of the stadium is reserved for visiting team's supporters. As a consequence, Milan enjoys much more crowd support than Inter. Therefore, by analyzing the existence of the home advantage in same-stadium derbies we are able to neutralize the other two factors (familiarity with the venue and travel fatigue) and identify the "pure" effect of the crowd support.

A recent study of Van de Ven (2011) investigates how crowd support contributes to the home advantage in derbies using the same idea that we exploit and data from the derbies of Milan and Rome. The author shows, surprisingly, that crowd support does not play any role in the home advantage and thus he argues that it is determined by travel fatigue and familiarity with the stadium. However, some features of this study could have affected its results: the author uses only a limited sample (64 matches), carries out t-test comparisons with "ad hoc" chosen teams, and does not use a regression analysis to control for other possible determinants of team performance. In sharp contrast, we do find that crowd support in same stadium derbies is an important determinant of team performance.

The paper is organized in the following way. Section 2 describes the dataset we use and presents some descriptive statistics. In Section 3 we carry out the empirical analysis, both for normal matches and for same stadium derbies. In Section 4 we focus on the referee's decisions. Section 5 concludes. 


\section{Data and Descriptive Statistics}

In the attempt to curb violence related to soccer events, especially after the tragedy of the Heysel Stadium in $1985,{ }^{3}$ in the early Nineties Italian stadiums were required all-seater accommodations and separate sectors between home and visiting supporters. The modernization of stadiums was also favored by the organization of the World Cup in Italy in 1990.

Given the neat separation between home and visiting supporters, in a typical match a large number of seats are reserved to the home team's season ticket holders; for the remaining seats, home teams - in charge of ticket sales - tend to favor their own supporters above that of away fans. Thus, only a part of the stadium is reserved to visiting supporters.

The disparity in the crowd supporting the home and the visiting team is the first element we exploit in our estimation strategy. The second element we take advantage of is the fact that in same stadium derbies - in contrast to other matches - there are no differences among teams in travel fatigue and in familiarity with the stadium. Therefore, in analyzing the performance of home and away teams in derbies - controlling for measures of teams' quality - we can safely relate any existing difference to crowd support, disentangling this effect from those related to travel fatigue and familiarity with the stadium.

Furthermore, we are able to compare the outcomes of teams in same-stadium derbies with the performance in "normal" matches that incorporate all the mechanisms affecting the home advantage. Therefore, any significant difference in the home advantage between these types of matches is suggestive of an impact due to travel fatigue and stadium familiarity.

In our empirical analysis we use two samples of data: 1) all the matches from 22 seasons of the Italian soccer league "Serie A" from 1991-1992 to 2012-2013; 2) the matches from same-stadium derbies played in the same 22 seasons. Our data have been collected from the websites of two leading Italian newspapers: "La Stampa" and "La Gazzetta dello Sport".

The Italian "Serie A" until the season 2003-2004 was composed by 18 teams, while in the following seasons there were 20 teams. In each season, teams played each other twice (both as the home and visiting team) for a total of 34 matches before 2003-04 and 38 matches after 2003-04. ${ }^{4}$ Therefore, we observe 7,398 matches. For each match we have available data on teams, goals scored, goals conceded, the place and the date when each game was played. For same stadium derbies we also collected penalties, yellow and red cards.

Team performance is measured using different indicators of the outcome obtained on the pitch: the number of points gained in each match by the teams (Points), the difference (Goals Difference) between the number of Goals Scored and the number of Goals Conceded. According to the rules of soccer, teams are awarded 3 points if they win a game, 1 point in case of draw and 0 points if they lose. The sum of the points

\footnotetext{
${ }^{3}$ Before the start of the 1985 European Cup Final between Juventus of Italy and Liverpool of England on 29 May 1985 in Brussels, a group of Liverpool fans breached a fence separating them from Juventus fans: escaping fans were pressed against a wall causing 39 deaths and about 600 injured.

${ }^{4}$ In the first half of the season each team plays once against all its opponents, while in the second half each team plays in the exact same order against the same teams, but a home game played in the first half will be an away game in the second half, and vice versa.
} 
obtained in each game determines the final ranking.

In order to explain team performance, we consider a number of alternative variables that capture differences in the quality of opposing teams and some measures of past performance: the difference in the ranking positions before the current match between the two teams (Ranking Difference); the difference in the total points (Total Points Difference) earned by the two teams in the season excluding the current match; the difference in points earned by the two teams, respectively, in the latest 4,8 and 12 matches. Since these measures are highly correlated, to avoid collinearity we use them separately in our regressions.

Descriptive statistics for all the matches are reported in Table 1.

Table 1. Descriptive Statistics. All matches in 22 seasons (1991-1992 to 2012-2013)

\begin{tabular}{lccccc}
\hline \hline Variable & Obs & Mean & Std. Dev. & Min & Max \\
\hline Year & 7398 & 2002.085 & 6.379 & 1991 & 2012 \\
Goals Home & 7398 & 1.529 & 1.237 & 0 & 8 \\
Goals Visitor & 7398 & 1.065 & 1.062 & 0 & 8 \\
Goals Difference & 7329 & 0.438 & 1.523 & -4 & 4 \\
Points Home & 7398 & 1.707 & 1.274 & 0 & 3 \\
Points Visitor & 7398 & 1.001 & 1.191 & 0 & 3 \\
Tot. Points Difference & 7398 & -0.706 & 20.328 & -70 & 68 \\
Ranking Difference & 7398 & -0.002 & 7.941 & -19 & 19 \\
Points Difference (Latest 4) & 7191 & -0.255 & 3.727 & -11 & 12 \\
Points Difference (Latest 8) & 7191 & -0.345 & 5.710 & -20 & 20 \\
Points Difference (Latest 12) & 7191 & -0.287 & 7.382 & -31 & 26 \\
\hline \hline
\end{tabular}

Source: La Stampa and La Gazzetta dello Sport websites.

The difference between Points Home and Points Visitor is 0.706 , highly statistically significant. One way to measure the home advantage is to determine the proportion of points earned by the home team with respect to the total points awarded. In our sample, the proportion of points for the home team is $63 \%$, a ratio in line with other main European championships (Pollard and Pollard, 2005). The Goals Difference between home and visitor is 0.438 .

In Table 2 we show descriptive statistics for same-stadium derbies. We observe derbies in Milan and Rome for all the 22 seasons ( 2 matches for each season); Turin for 10; Genoa for 9; Verona for 1, for a total of 128 observations. ${ }^{5}$ The difference between the home and the visiting team in Points (0.44) and in Goals (0.20) is large, although less pronounced than in normal matches.

\footnotetext{
${ }^{5}$ Same-stadium derbies are matches between Milan vs. Internazionale (in Milan); Juventus vs. Turin (Turin); Rome vs. Lazio (Rome); Genoa vs. Sampdoria (Genoa); Verona vs. Chievo Verona (Verona). Some of these teams are not top clubs and played in Serie A only for a few seasons. Since the season 2011-2012 Juventus has its own stadium and the matches against Turin are no longer considered "same-stadium derbies".
} 
Table 2. Descriptive Statistics - Same Stadium Derbies

\begin{tabular}{|c|c|c|c|c|c|}
\hline Variable & Obs & Mean & Std. Dev. & Min & Max \\
\hline Goals Home & 128 & 1.430 & 1.175 & 0 & 5 \\
\hline Goals Visitor & 128 & 1.242 & 1.114 & 0 & 6 \\
\hline Goals Difference & 128 & 0.219 & 1.374 & -3 & 3 \\
\hline Points Home & 128 & 1.563 & 1.272 & 0 & 3 \\
\hline Points Visitor & 128 & 1.117 & 1.214 & 0 & 3 \\
\hline Tot. Points Difference & 128 & -0.445 & 18.547 & -48 & 48 \\
\hline Ranking Difference & 128 & 0.000 & 6.690 & -17 & 17 \\
\hline Points Difference (Latest 4) & 128 & -0.312 & 3.751 & -11 & 8 \\
\hline Points Difference (Latest 8) & 128 & -0.594 & 5.539 & -18 & 16 \\
\hline Points Difference (Latest 12) & 128 & -0.492 & 7.469 & -18 & 20 \\
\hline
\end{tabular}

Notes: Only same stadium derbies in 22 seasons. Source: La Stampa and La Gazzetta dello Sport.

\section{Home Advantage in Derbies and in Other Matches: Empirical Results}

In this Section, to evaluate the extent of the home advantage, we estimate the impact of playing at home on team performance using as dependent variable firstly Points Home - estimating an Ordered Probit Model given the ordinal nature of this variable (win, draw and loss) - and then Goals Difference - estimating with OLS. In both cases, we contrast the effect of playing at home in normal matches with that emerging in samestadium derbies.

Following Garicano and Palacios-Huerta (2005) we consider each match twice, from the perspective of the home team and from the perspective of the visiting team, clustering standard errors at the match level. As a robustness check, we choose to randomly assign each match either to the home or to the visiting team considering each match only once. As we will show below, the results we find using the second procedure are almost identical.

To capture the home advantage we simply use the dummy Home (equal to one if the game is played at home and zero if it is played away). We do not have information on crowd size or on the number of supporters of each team. Although some studies proxy the home factor with the crowd size (or crowd density, the number of people relative to the stadium's capacity), we believe that the use of crowd size measures could lead to several estimation biases, since crowd size is likely correlated either to the quality of the home team or to the quality of the visiting team. In fact, if the home team is performing well, crowd size tends to be larger: thus, it is hard to distinguish the impact on the outcome of a stronger team from the effect of a larger crowd, creating an upward bias; on the other hand, crowd size could be greater when the visiting team is a high quality team or has many top players, imparting a downward bias on the estimated effect. Using simply the dummy Home we avoid these problems, since Home is assigned randomly and is not related to the quality of the teams or to other unobservable factors. ${ }^{6}$

In Table 3 we estimate a model for Points with Ordered Probit, considering all the matches played in 22 seasons (7398). In the last row of Table 3 we report the marginal effects of Home for the outcome of win. In column (1) the effect of playing at home is estimated without adding other explanatory variables. We find

\footnotetext{
${ }^{6}$ This corresponds to the reduced form of a model in which team performance is determined by the crowd support and this, in turn, is determined by playing at home.
} 
that the impact is strong and highly significant ( $t$-stat is around 25). On the basis of the marginal effects, playing at home causes an increase in the probability of winning the match of about 23 percentage points.

In column (2) we control for Total Points Difference (the difference of points earned by the two teams in the season excluding the current match). We show that the difference in the points earned constitutes a strong predictor of the current team performance. The variable Home has a slightly stronger effect with respect to the first specification: the probability of winning if playing at home is 26 percentage points higher.

We find almost the same results for the home advantage in column (3), controlling for the Ranking Difference between the two teams. In columns (4) and (5), we control for the difference in points between the two opposing teams in, respectively, the latest four and eight matches. Again, we find a very strong positive effect of playing at home. The variables measuring the relative quality of the teams have always the expected impact on the outcome of the match. Furthermore, we obtain very similar results using as control the variable Points Difference (Latest 12) (not reported).

Table 3. Home Advantage and Team Performance for all Matches. Ordered Probit Estimates. Dependent Variable: Points

\begin{tabular}{|c|c|c|c|c|c|}
\hline & (1) & (2) & (3) & (4) & (5) \\
\hline Home & $\begin{array}{c}0.6469 * * * \\
(0.0267)\end{array}$ & $\begin{array}{c}0.7424 * * * \\
(0.0276)\end{array}$ & $\begin{array}{c}0.7417 * * * \\
(0.0279)\end{array}$ & $\begin{array}{l}0.7001 * * * \\
(0.0275)\end{array}$ & $\begin{array}{c}0.7211 * * * \\
(0.0277)\end{array}$ \\
\hline Tot. Points Difference & & $\begin{array}{c}0.0224 * * * \\
(0.0007)\end{array}$ & & & \\
\hline Ranking Difference & & & $\begin{array}{c}-0.0707 * * * \\
(0.0018)\end{array}$ & & \\
\hline Points Difference (Latest 4) & & & & $\begin{array}{l}0.0639 * * * \\
(0.0037)\end{array}$ & \\
\hline Points Difference (Latest 8) & & & & & $\begin{array}{c}0.0564 * * * \\
(0.0025)\end{array}$ \\
\hline Cut1 & $\begin{array}{c}-0.0705 * * * \\
(0.0146)\end{array}$ & $\begin{array}{c}-0.0617 * * * \\
(0.0151)\end{array}$ & $\begin{array}{c}-0.0834 * * * \\
(0.0154)\end{array}$ & $\begin{array}{c}-0.0531 * * * \\
(0.0150)\end{array}$ & $\begin{array}{c}-0.0514 * * * \\
(0.0151)\end{array}$ \\
\hline Cut2 & $\begin{array}{c}0.7174 * * * \\
(0.0160)\end{array}$ & $\begin{array}{c}0.8041 * * * \\
(0.0170)\end{array}$ & $\begin{array}{c}0.8252 * * * \\
(0.0173)\end{array}$ & $\begin{array}{l}0.7532 * * * \\
(0.0166)\end{array}$ & $\begin{array}{c}0.7725 * * * \\
(0.0168)\end{array}$ \\
\hline Observations & 14796 & 14796 & 14796 & 14382 & 14382 \\
\hline Pseudo R-squared & 0.036 & 0.101 & 0.132 & 0.056 & 0.070 \\
\hline $\begin{array}{l}\text { Marginal Effect of Home } \\
\text { for the Outcome = Win }\end{array}$ & $\begin{array}{c}0.2351 * * * \\
(0.0094)\end{array}$ & $\begin{array}{c}0.2647 * * * \\
(0.0094)\end{array}$ & $\begin{array}{c}0.2621 * * * \\
(0.0094)\end{array}$ & $\begin{array}{l}0.2532 * * * \\
(0.0096)\end{array}$ & $\begin{array}{c}0.2596 * * * \\
(0.0095)\end{array}$ \\
\hline
\end{tabular}

Notes: The Table reports Ordered Probit estimates. Standard errors (reported in parentheses) are corrected for heteroskedasticity and allowing for clustering at the match level. The symbols ***, **, * indicate that coefficients are statistically significant, respectively, at the 1,5 , and 10 percent level.

As discussed in the literature, the strong impact on team performance of playing at home could be due to several factors: crowd support (referee bias or encouragement of home players), familiarity with the venue or the environment, travel fatigue for the visiting team.

To evaluate the relevance of crowd support and simultaneously isolate the effect of the other two factors contributing to the home advantage, in Table 4 we estimate the impact of playing at home focusing exclusively on same-stadium derbies (128 matches). As explained in details in Section 2, this allows us to rigorously estimate the role played by crowd support in the home advantage, by neutralizing both the effects 
of players' familiarity with the venue and the effects of travel fatigue. In fact, the latter factors are equivalent for the two opposing teams in a derby.

Notwithstanding a much lower number of observations (128 instead of 7,398) we find a strong and significant effect of playing at home. The coefficient on Home ranges between 0.41 to 0.45 , significant at the 5 percent level. In terms of marginal effects (the last row of Table 4), we show that playing at home in local derbies increases the probability of winning of about 15-16 percentage points.

Estimation results point out a sizable difference in the extent of the home advantage in normal matches with respect to same-stadium derbies: the home advantage is larger in normal matches of about 8-10 percentage points in terms of probability of winning the match. Therefore, one might speculate that the crowd support effect contributes for about 60\% (15 points out of 25) to the home advantage, whereas both familiarity and travel fatigue account for the remaining $40 \%$.

Table 4. Home Advantage in Derbies. Ordered Probit Estimates. Dependent Variable: Points

\begin{tabular}{|c|c|c|c|c|c|}
\hline & (1) & (2) & (3) & (4) & (5) \\
\hline Home & $\begin{array}{l}0.4090 * * \\
(0.2010)\end{array}$ & $\begin{array}{l}0.4382 * * \\
(0.2029)\end{array}$ & $\begin{array}{l}0.4437 * * \\
(0.2045)\end{array}$ & $\begin{array}{c}0.4276^{* *} \\
(0.2041)\end{array}$ & $\begin{array}{c}0.4510^{* *} \\
(0.2061)\end{array}$ \\
\hline Tot. Points Difference & & $\begin{array}{l}0.0149 * * * \\
(0.0057)\end{array}$ & & & \\
\hline Ranking Difference & & & $\begin{array}{c}-0.0588 * * * \\
(0.0145)\end{array}$ & & \\
\hline Points Difference (Latest 4) & & & & $\begin{array}{c}0.0242 \\
(0.0274)\end{array}$ & \\
\hline Points Difference (Latest 8) & & & & & $\begin{array}{r}0.0283 \\
(0.0176) \\
\end{array}$ \\
\hline Cut1 & $\begin{array}{l}-0.2171^{*} \\
(0.1122)\end{array}$ & $\begin{array}{l}-0.2176^{*} \\
(0.1136)\end{array}$ & $\begin{array}{c}-0.2311 * * \\
(0.1149)\end{array}$ & $\begin{array}{l}-0.2093^{*} \\
(0.1128)\end{array}$ & $\begin{array}{l}-0.2009^{*} \\
(0.1132)\end{array}$ \\
\hline Cut2 & $\begin{array}{l}0.6261 * * * \\
(0.1195)\end{array}$ & $\begin{array}{l}0.6559 * * * \\
(0.1219)\end{array}$ & $\begin{array}{l}0.6750 * * * \\
(0.1238)\end{array}$ & $\begin{array}{c}0.6370 * * * \\
(0.1218)\end{array}$ & $\begin{array}{c}0.6519 * * * \\
(0.1235)\end{array}$ \\
\hline Observations & 256 & 256 & 256 & 256 & 256 \\
\hline Pseudo R-squared & 0.015 & 0.040 & 0.065 & 0.018 & 0.023 \\
\hline $\begin{array}{l}\text { Marginal Effect of Home } \\
\text { for the Outcome = Win }\end{array}$ & $\begin{array}{l}0.1479 * * \\
(0.0705)\end{array}$ & $\begin{array}{l}0.1579 * * \\
(0.0720)\end{array}$ & $\begin{array}{l}0.1587 * * \\
(0.0720)\end{array}$ & $\begin{array}{c}0.1550^{* *} \\
(0.0728)\end{array}$ & $\begin{array}{l}0.1632 * * \\
(0.0732)\end{array}$ \\
\hline
\end{tabular}

Notes: The Table reports Ordered Probit estimates. Standard errors (reported in parentheses) are corrected for heteroskedasticity and allowing for clustering at the match level. The symbols $* * *, * *, *$ indicate that coefficients are statistically significant, respectively, at the 1,5 , and 10 percent level.

To check whether our results are affected by the use of two observations for each match, in Table 5 we report the estimates of the coefficient on Home using only one observation for each match, randomly assigning the match to the perspective of the home or the visiting team. Comparing respectively the coefficients on the first row of Table 5 with the coefficients on Home in Table 3 and the coefficients in the second row of Table 5 with the coefficients of Table 4, we show that the results (both in terms of the magnitude of coefficients and standard errors) are almost identical following the two alternative procedures. 
Table 5. Home Advantage in Normal Matches and Derbies Using One Observation for Each Match

\begin{tabular}{|c|c|c|c|c|c|}
\hline & (1) & (2) & (3) & (4) & (5) \\
\hline Home (All Matches) & $\begin{array}{c}0.6469 * * * \\
(0.0267)\end{array}$ & $\begin{array}{c}0.7426 * * * \\
(0.0276)\end{array}$ & $\begin{array}{c}0.7419 * * * \\
(0.0278)\end{array}$ & $\begin{array}{c}0.7001 * * * \\
(0.0275)\end{array}$ & $\begin{array}{c}0.7213 * * * \\
(0.0277)\end{array}$ \\
\hline Home (Derbies) & $\begin{array}{c}0.3965 * * \\
(0.2020)\end{array}$ & $\begin{array}{c}0.4267 * * \\
(0.2039)\end{array}$ & $\begin{array}{c}0.4332 * * \\
(0.2056)\end{array}$ & $\begin{array}{c}0.4148 * * \\
(0.2052)\end{array}$ & $\begin{array}{c}0.4391 * * \\
(0.2069)\end{array}$ \\
\hline
\end{tabular}

Notes: The Table reports Ordered Probit estimates. In the first row we report only the coefficient on Home using the same specifications as in Table 3. In the second row we report the coefficient using the same specifications as in Table 4. Standard errors (reported in parentheses) are corrected for heteroskedasticity. The symbols ***, **, * indicate that coefficients are statistically significant, respectively, at the 1, 5, and 10 percent level.

To better evaluate the difference in the home advantage between same-stadium derbies and normal matches, we first build a dummy Derby equal to one for same-stadium derbies and 0 otherwise. Then, in Table 6 we use all the observations, including an interaction between Derby and Home, to estimate the difference between the home advantage enjoyed in normal matches and the home advantage in derbies. In these estimates, Home measures the effect of playing at home in normal matches, whereas the combination of Home and Home*Derby gives the effect of playing at home in derbies.

Table 6. Home Advantage: Joint Estimates with Interactions. Ordered Probit Estimates. Dependent Variable: Points

\begin{tabular}{|c|c|c|c|c|c|}
\hline & $(1)$ & (2) & (3) & $(4)$ & $(5)$ \\
\hline Home & $\begin{array}{c}0.6513 * * * \\
(0.0270)\end{array}$ & $\begin{array}{c}0.7477 * * * \\
(0.0279)\end{array}$ & $\begin{array}{c}0.7489 * * * \\
(0.0281)\end{array}$ & $\begin{array}{c}0.7046 * * * \\
(0.0278)\end{array}$ & $\begin{array}{c}0.7251 * * * \\
(0.0279)\end{array}$ \\
\hline Derby & $\begin{array}{c}0.1247 \\
(0.0991)\end{array}$ & $\begin{array}{c}0.1471 \\
(0.1041)\end{array}$ & $\begin{array}{c}0.1531 \\
(0.1042)\end{array}$ & $\begin{array}{c}0.1252 \\
(0.1015)\end{array}$ & $\begin{array}{c}0.1172 \\
(0.1026)\end{array}$ \\
\hline Home*Derby & $\begin{array}{l}-0.2493 \\
(0.1982)\end{array}$ & $\begin{array}{l}-0.2942 \\
(0.2082)\end{array}$ & $\begin{array}{l}-0.3067 \\
(0.2082)\end{array}$ & $\begin{array}{l}-0.2504 \\
(0.2031)\end{array}$ & $\begin{array}{l}-0.2344 \\
(0.2053)\end{array}$ \\
\hline Tot. Points Difference & & $\begin{array}{c}0.0224 * * * \\
(0.0007)\end{array}$ & & & \\
\hline Ranking Difference & & & $\begin{array}{c}-0.0710 * * * \\
(0.0018)\end{array}$ & & \\
\hline Points Difference (Latest 4) & & & & $\begin{array}{c}0.0639 * * * \\
(0.0037)\end{array}$ & \\
\hline Points Difference (Latest 8) & & & & & $\begin{array}{c}0.0564 * * * \\
(0.0025)\end{array}$ \\
\hline Cut1 & $\begin{array}{c}-0.0684 * * * \\
(0.0147)\end{array}$ & $\begin{array}{c}-0.0591 * * * \\
(0.0152)\end{array}$ & $\begin{array}{c}-0.0804 * * * \\
(0.0155)\end{array}$ & $\begin{array}{c}-0.0509 * * * \\
(0.0151)\end{array}$ & $\begin{array}{c}-0.0495 * * * \\
(0.0152)\end{array}$ \\
\hline Cut2 & $\begin{array}{c}0.7197 * * * \\
(0.0161)\end{array}$ & $\begin{array}{c}0.8069 * * * \\
(0.0171)\end{array}$ & $\begin{array}{c}0.8292 * * * \\
(0.0174)\end{array}$ & $\begin{array}{c}0.7556 * * * \\
(0.0167)\end{array}$ & $\begin{array}{c}0.7745 * * * \\
(0.0169)\end{array}$ \\
\hline $\begin{array}{l}\text { Observations } \\
\text { Pseudo R-squared }\end{array}$ & $\begin{array}{l}14796 \\
0.036\end{array}$ & $\begin{array}{l}14796 \\
0.101\end{array}$ & $\begin{array}{l}14796 \\
0.133\end{array}$ & $\begin{array}{l}14382 \\
0.056\end{array}$ & $\begin{array}{l}14382 \\
0.071\end{array}$ \\
\hline Home (no Derbies) & $\begin{array}{c}0.2369 * * * \\
(0.0095)\end{array}$ & $\begin{array}{c}0.2666^{* * * *} \\
(0.0095)\end{array}$ & $\begin{array}{c}0.2645 * * * \\
(0.0095)\end{array}$ & $\begin{array}{c}0.2547 * * * \\
(0.0096)\end{array}$ & $\begin{array}{c}0.2610 * * * \\
(0.0096)\end{array}$ \\
\hline Home (in Derbies) & $\begin{array}{c}0.1476 * * \\
(0.0713)\end{array}$ & $\begin{array}{l}0.1636 * * \\
(0.0734)\end{array}$ & $\begin{array}{l}0.1581 * * \\
(0.0728)\end{array}$ & $\begin{array}{c}0.1659 * * \\
(0.0724)\end{array}$ & $\begin{array}{c}0.1783 * * \\
(0.0727)\end{array}$ \\
\hline
\end{tabular}

Notes: The Table reports Ordered Probit estimates. Standard errors (reported in parentheses) are corrected for heteroskedasticity and allowing for clustering at the match level. The symbols $* * *, * *, *$ indicate that coefficients are statistically significant, respectively, at the 1,5 , and 10 percent level.

Although the statistical significance of the interaction is not strong (the $p$-value ranges between 0.14 to 0.20 ), the evidence suggests that in derbies a lower home advantage emerges. In the joint estimations, we 
find - in line with separate estimates obtained in Tables 3 and 4 - that the marginal effects of winning if playing at home are equal to about 25 percentage points for normal matches and 16 points for derbies (last two rows in Table 6).

\subsection{Using Alternative Measures of Performance: Goals Difference}

To check the robustness of our findings, in Tables 7 and 8 we evaluate the impact of playing at home on an alternative measure of team performance, Goals Difference, instead of Points.

Using all the matches, we estimate with OLS the same specifications of Table $4 .^{7}$ We find that playing at home increases the Goals Difference for the home team from 0.87 to 0.92 according to the specification ( $t$-stat is always above 25$)$.

Table 7. Home Advantage in Goals Difference. All matches. OLS Estimates

\begin{tabular}{|c|c|c|c|c|c|}
\hline & (1) & (2) & (3) & (4) & (5) \\
\hline Home & $\begin{array}{c}0.8700 * * * \\
(0.0343)\end{array}$ & $\begin{array}{c}0.9096 * * * \\
(0.0316)\end{array}$ & $\begin{array}{c}0.8687 * * * \\
(0.0306)\end{array}$ & $\begin{array}{c}0.9161 * * * \\
(0.0339)\end{array}$ & $\begin{array}{c}0.9231 * * * \\
(0.0332)\end{array}$ \\
\hline Tot. Points Difference & & $\begin{array}{c}0.0281 * * * \\
(0.0007)\end{array}$ & & & \\
\hline Ranking Difference & & & $\begin{array}{c}-0.0833 * * * \\
(0.0018)\end{array}$ & & \\
\hline Points Difference (Latest 4) & & & & $\begin{array}{c}0.0877 * * * \\
(0.0045)\end{array}$ & \\
\hline Points Difference (Latest 8) & & & & & $\begin{array}{c}0.0754 * * * \\
(0.0028)\end{array}$ \\
\hline Constant & $\begin{array}{c}-0.4350 * * * \\
(0.0171)\end{array}$ & $\begin{array}{c}-0.4548 * * * \\
(0.0158)\end{array}$ & $\begin{array}{c}-0.4344 * * * \\
(0.0153)\end{array}$ & $\begin{array}{c}-0.4581 * * * \\
(0.0169)\end{array}$ & $\begin{array}{c}-0.4616 * * * \\
(0.0166)\end{array}$ \\
\hline Observations & 14796 & 14796 & 14796 & 14382 & 14382 \\
\hline Adjusted R-squared & 0.080 & 0.218 & 0.266 & 0.125 & 0.159 \\
\hline
\end{tabular}

Notes: The Table reports OLS estimates. Standard errors (reported in parentheses) are corrected for heteroskedasticity and allowing for clustering at the match level. The symbols $* * *, * * *$ indicate that coefficients are statistically significant, respectively, at the 1,5 , and 10 percent level.

As regards the home advantage in same-stadium derbies, we find in Table 8 that there is a strong and significant effect of about 0.44 goals more for the home team (almost significant at the 5 percent level), although the magnitude tends to be smaller than in normal matches.

${ }^{7}$ We set Goals Difference equal to 3 if it is above 3 (in $3 \%$ of the sample) to attenuate the influence of outliers. 
Table 8. Home Advantage in Goals Difference in Same-Stadium Derbies. OLS Estimates

\begin{tabular}{|c|c|c|c|c|c|}
\hline & (1) & (2) & (3) & (4) & (5) \\
\hline Home & $\begin{array}{l}0.4375^{*} \\
(0.2434)\end{array}$ & $\begin{array}{c}0.4498^{*} \\
(0.2386)\end{array}$ & $\begin{array}{l}0.4401 * \\
(0.2346)\end{array}$ & $\begin{array}{l}0.4308^{*} \\
(0.2439)\end{array}$ & $\begin{array}{c}0.4557^{*} \\
(0.2435)\end{array}$ \\
\hline Tot. Points Difference & & $\begin{array}{c}0.0139 * * \\
(0.0062)\end{array}$ & & & \\
\hline Ranking Difference & & & $\begin{array}{c}-0.0558 * * * \\
(0.0148)\end{array}$ & & \\
\hline Points Difference (Latest 4) & & & & $\begin{array}{l}-0.0108 \\
(0.0352)\end{array}$ & \\
\hline Points Difference (Latest 8) & & & & & $\begin{array}{c}0.0153 \\
(0.0205)\end{array}$ \\
\hline Constant & $\begin{array}{c}-0.2188^{*} \\
(0.1217)\end{array}$ & $\begin{array}{c}-0.2249 * \\
(0.1193)\end{array}$ & $\begin{array}{c}-0.2201 * \\
(0.1173)\end{array}$ & $\begin{array}{c}-0.2154 * \\
(0.1219)\end{array}$ & $\begin{array}{c}-0.2278 * \\
(0.1218)\end{array}$ \\
\hline Observations & 256 & 256 & 256 & 256 & 256 \\
\hline Adjusted R-squared & 0.021 & 0.052 & 0.090 & 0.018 & 0.021 \\
\hline
\end{tabular}

Notes: The Table reports OLS estimates. Standard errors (reported in parentheses) are corrected for heteroskedasticity and allowing for clustering at the match level. The symbols $* * *, * *$, * indicate that coefficients are statistically significant, respectively, at the 1,5 , and 10 percent level.

All our estimates consistently show that home teams enjoy a sizable advantage also in same-stadium derbies, when the differences in players' familiarity with the stadium and travel fatigue are neutralized. This points to an effect of crowd support for the home team, enjoying a larger number of supporters when playing at home in local derbies.

It remains to be seen whether the crowd affects the match outcome mainly through the encouragement of players or through its influence on the referee's decisions. In the next section we try to investigate the possible impact of home supporters on some referees' decisions.

\section{Home Crowd Support and Referees' Decisions}

To evaluate the effects of home crowd support on referees' behavior, we consider some relevant discretionary decisions of officials for the home and visiting teams: awarding yellow cards, red cards and penalties. The data on these decisions have been gathered only for derbies, since they are not readily available and need to be collected one-by-one for each match.

Descriptive statistics for referee's decisions are reported in Table 9. In each match, referees award on average 2.69 yellow cards, 0.27 red cards and 0.17 penalties. Home teams seem to receive more favorable treatments: penalties are awarded significantly more often to the home team; red cards are given significantly more to the visiting team, while yellow cards awarded to the home and to the visiting team are not significantly different. 
Table 9. Descriptive Statistics: Referee's Decisions in Derbies

\begin{tabular}{lccccc}
\hline \hline Variable & Obs & Mean & Std. Dev. & Min & Max \\
\hline Yellow Cards: Home & 128 & 2.648 & 1.220 & 0 & 6 \\
Yellow Cards: Visiting & 128 & 2.727 & 1.424 & 0 & 8 \\
Red Cards: Home & 128 & 0.227 & 0.456 & 0 & 2 \\
Red Cards: Visiting & 128 & 0.313 & 0.599 & 0 & 3 \\
Penalties: Home & 128 & 0.195 & 0.436 & 0 & 2 \\
Penalties: Visiting & 128 & 0.148 & 0.399 & 0 & 2 \\
Disciplinary Sanctions Difference & 128 & -0.336 & 2.178 & -8 & 5 \\
Penalties Difference & 128 & 0.047 & 0.515 & -2 & 2 \\
Referee's Decisions & 128 & 0.477 & 2.834 & -8 & 9 \\
\hline \hline
\end{tabular}

Source: La Stampa and La Gazzetta dello Sport.

In order to use a synthetic measure of referee disciplinary sanctions, we build a variable Disciplinary Sanctions Difference as:

\section{Disciplinary Santions Difference $=($ Yellow Card Home $+3 *$ Red Card Home $)-$ (YellowCard Visiting $+3 *$ Red Card Visiting)}

in which we take the difference of the number of disciplinary sanctions between the home and visiting team, weighting red cards three times as yellow cards (given that a red card entails that the player is sent off and his team must continue the game with one less player).

Using OLS, we estimate whether there is a significant difference in disciplinary sanctions between the home team and the visiting team. In columns (1), (2) and (3) of Table 10, in which we include, respectively, no controls, a control for Total Points Difference, and a control for Ranking Difference, we show that the home team is awarded significantly less disciplinary sanctions by referees than the visiting team.

To give account of all referees' decisions (disciplinary sanctions and penalties) we also build the variable Referee's Decisions Difference as:

\section{Referee Decisions Difference $=(3 *$ PenaltiesHome - Yellow Card Home $-3 *$ Red Card Home $)-$ (3* PenaltiesVisiting -YellowCard Visiting $-3 *$ Red Card Visiting)}

in which in this case penalties awarded to the home team enter positively while yellow and red cards for the home team enter negatively (and vice versa for the visiting team). Moreover, penalties and red cards are weighted three times as yellow cards (using alternative weights leads to very similar results). Positive values of the variable Referee's Decisions Difference represents decisions favoring the home team and vice versa.

Using the same control variables of the first three columns, in specifications (4), (5) and (6) of Table 10 we show that referee's decisions in derbies tend to favor the home team, while the variables accounting for the quality of teams (Tot. Points Difference, Ranking Difference) do not seem to influence referees' decisions.

These findings reassuringly confirm for same-stadium derbies a well-established result (Sutter and Kocher, 2004; Garicano et al., 2005; Dawson and Dobson, 2010, among others), that is, the existence of home bias of referees which tend to penalize home teams less often than they do for visiting teams. 
Table 10. Disciplinary Sanctions and other Referee's Decisions in Derbies

\begin{tabular}{|c|c|c|c|c|c|c|}
\hline & $\begin{array}{c}(1) \\
\text { Disciplinary } \\
\text { Sanctions }\end{array}$ & $\begin{array}{c}(2) \\
\text { Disciplinary } \\
\text { Sanctions }\end{array}$ & $\begin{array}{c}(3) \\
\text { Disciplinary } \\
\text { Sanctions }\end{array}$ & $\begin{array}{c}(4) \\
\text { Referee's } \\
\text { Decisions }\end{array}$ & $\begin{array}{c}\text { (5) } \\
\text { Referee's } \\
\text { Decisions } \\
\end{array}$ & $\begin{array}{c}(6) \\
\text { Referee's } \\
\text { Decisions } \\
\end{array}$ \\
\hline Home & $\begin{array}{l}-0.6719 * \\
(0.3858)\end{array}$ & $\begin{array}{l}-0.6792 * \\
(0.3871)\end{array}$ & $\begin{array}{l}-0.6708 * \\
(0.3829)\end{array}$ & $\begin{array}{l}0.9531 * \\
(0.5020)\end{array}$ & $\begin{array}{l}0.9544 * \\
(0.5040)\end{array}$ & $\begin{array}{l}0.9523 * \\
(0.5011)\end{array}$ \\
\hline Tot. Points Difference & & $\begin{array}{l}-0.0083 \\
(0.0107)\end{array}$ & & & $\begin{array}{c}0.0014 \\
(0.0126)\end{array}$ & \\
\hline Ranking Difference & & & $\begin{array}{c}0.0440 \\
(0.0287)\end{array}$ & & & $\begin{array}{c}-0.0350 \\
(0.0327)\end{array}$ \\
\hline Constant & $\begin{array}{l}0.3359 * \\
(0.1929)\end{array}$ & $\begin{array}{l}0.3396^{*} \\
(0.1936)\end{array}$ & $\begin{array}{l}0.3352 * \\
(0.1914)\end{array}$ & $\begin{array}{c}-0.4766^{*} \\
(0.2510)\end{array}$ & $\begin{array}{c}-0.4772 * \\
(0.2520)\end{array}$ & $\begin{array}{c}-0.4760 * \\
(0.2505)\end{array}$ \\
\hline Observations & 256 & 256 & 256 & 256 & 256 & 256 \\
\hline Adjusted R-squared & 0.020 & 0.021 & 0.034 & 0.024 & 0.020 & 0.027 \\
\hline
\end{tabular}

Notes: The Table reports OLS estimates. Standard errors (reported in parentheses) are corrected for heteroskedasticity and allowing for clustering at the match level. The symbols $* * *, * * *$ indicate that coefficients are statistically significant, respectively, at the 1,5 , and 10 percent level.

\subsection{The Impact of Playing at Home taking as Constant Referee's Decisions}

In the previous Section we have shown that the home team in same-stadium derbies, thanks to the support of the crowd, not only attain better outcomes but also tend to benefit from more favorable referee's decisions.

It would be interesting to verify if - taking as constant the penalty and disciplinary decisions of the referee - the home team receives further benefits from the support of the crowd or, alternatively, if in samestadium derbies the home advantage derives exclusively from the biased decisions of referees.

To this aim, an interesting attempt is to regress measures of teams' performance on the Home dummy, on measures of teams' quality, controlling, in addition, for the variable Referee's Decisions. In this way, the coefficient on the Home captures any effect of playing at home, taking as constant the potentially biased referee's decisions. If all the advantages of playing at home go through more favorable referee's decisions, we should find that the variable Referee's Decisions is significant in explaining performance, while Home should have no additional effect. On the other hand, if Home were significant when controlling for Referee's Decisions, this would imply that playing at home gives additional advantages with respect to the influence of referees' decisions.

It is worthwhile to note that this evidence can be considered only suggestive, both because we do not have a comprehensive measure of all the decisions taken by the referee in a match (off-sides, free kicks, etc.) and because referee's decisions could be themselves the consequence of higher motivation and effort provided by the home players in turn stimulated by the crowd support.

In Table 11 we use as dependent variable Points and we estimate with Ordered Probit the same models of Table 4 but using as additional control Referee's Decisions. In all the specifications we find that Referee's Decisions has a direct positive impact on the outcome of the match. However - taking as constant the influence of referee's decisions on the match outcome - we find that Home has still a positive and significant impact on Points.

In the last row of Table 11 we calculate the probability of winning the match if playing at home given referee's decisions: we find that the probability increases of about 13 percentage points. Therefore, 
taking as constant referee's decisions, we show that a large role is played by the support of the crowd, presumably through the encouragement and the motivation of players.

Table 11. The impact of playing at home controlling for referee's decisions. Ordered Probit Estimates. Dependent variable: Points

\begin{tabular}{|c|c|c|c|c|c|}
\hline & (1) & (2) & (3) & (4) & (5) \\
\hline Home & $\begin{array}{l}0.3466^{*} \\
(0.2070)\end{array}$ & $\begin{array}{l}0.3763 * \\
(0.2087)\end{array}$ & $\begin{array}{l}0.3839 * \\
(0.2097)\end{array}$ & $\begin{array}{l}0.3659 * \\
(0.2100)\end{array}$ & $\begin{array}{c}0.3897^{*} \\
(0.2115)\end{array}$ \\
\hline Referee's Decisions & $\begin{array}{l}0.0715^{*} \\
(0.0393)\end{array}$ & $\begin{array}{l}0.0699 * \\
(0.0402)\end{array}$ & $\begin{array}{c}0.0611 \\
(0.0407)\end{array}$ & $\begin{array}{l}0.0730 * \\
(0.0397)\end{array}$ & $\begin{array}{l}0.0757 * \\
(0.0399)\end{array}$ \\
\hline Tot. Points Difference & & $\begin{array}{c}0.0148 * * * \\
(0.0057)\end{array}$ & & & \\
\hline Ranking Difference & & & $\begin{array}{c}-0.0569 * * * \\
(0.0146)\end{array}$ & & \\
\hline Points Difference (Latest 4) & & & & $\begin{array}{c}0.0266 \\
(0.0275)\end{array}$ & \\
\hline Points Difference (Latest 8) & & & & & $\begin{array}{c}0.0311^{*} \\
(0.0173) \\
\end{array}$ \\
\hline Observations & 256 & 256 & 256 & 256 & 256 \\
\hline Pseudo R-squared & 0.029 & 0.053 & 0.075 & 0.032 & 0.039 \\
\hline $\begin{array}{l}\text { Marginal Effect of Home } \\
\text { for the Outcome = Win }\end{array}$ & $\begin{array}{l}0.1256^{*} \\
(0.0743) \\
\end{array}$ & $\begin{array}{l}0.1353 * \\
(0.0742) \\
\end{array}$ & $\begin{array}{l}0.1371 * \\
(0.0740) \\
\end{array}$ & $\begin{array}{l}0.1324 * \\
(0.0752) \\
\end{array}$ & $\begin{array}{l}0.1407 * \\
(0.0754) \\
\end{array}$ \\
\hline
\end{tabular}

Notes: The Table reports Ordered Probit estimates. Standard errors (reported in parentheses) are corrected for heteroskedasticity and allowing for clustering at the match level. The symbols $* * *, * *, *$ indicate that coefficients are statistically significant, respectively, at the 1,5 , and 10 percent level.

We find similar results in Table 12 in which we use as dependent variable Goals Difference (instead of Points) between the home and the visiting team. Similarly to Table 8 we show that playing at home increases of about 0.35 the goals difference between the two opposing teams. These effects are rather imprecisely estimated given the low number of observations ( $p$-values are around 0.15). Again our estimates suggest the existence of a crowd support effect on the home advantage that arises through players' performance, in addition to the influence on referees' behavior. 
Table 12. The impact of playing at home controlling for referee's decisions. OLS Estimates. Dependent variable: Goals Difference

\begin{tabular}{|c|c|c|c|c|c|}
\hline & (1) & (2) & (3) & (4) & $(5)$ \\
\hline Home & $\begin{array}{c}0.3378 \\
(0.2490)\end{array}$ & $\begin{array}{c}0.3508 \\
(0.2438)\end{array}$ & $\begin{array}{c}0.3465 \\
(0.2400)\end{array}$ & $\begin{array}{c}0.3346 \\
(0.2484)\end{array}$ & $\begin{array}{c}0.3581 \\
(0.2481)\end{array}$ \\
\hline Referee's Decisions & $\begin{array}{c}0.1046 * * \\
(0.0470)\end{array}$ & $\begin{array}{c}0.1038^{* *} \\
(0.0476)\end{array}$ & $\begin{array}{l}0.0942 * \\
(0.0477)\end{array}$ & $\begin{array}{c}0.1041 * * \\
(0.0469)\end{array}$ & $\begin{array}{c}0.1074 * * \\
(0.0476)\end{array}$ \\
\hline Tot. Points Difference & & $\begin{array}{c}0.0137 * * \\
(0.0061)\end{array}$ & & & \\
\hline Ranking Difference & & & $\begin{array}{c}-0.0533 * * * \\
(0.0149)\end{array}$ & & \\
\hline Points Difference (Latest 4) & & & & $\begin{array}{l}-0.0059 \\
(0.0345)\end{array}$ & \\
\hline Points Difference (Latest 8) & & & & & $\begin{array}{c}0.0193 \\
(0.0197)\end{array}$ \\
\hline Constant & $\begin{array}{l}-0.1689 \\
(0.1245)\end{array}$ & $\begin{array}{l}-0.1754 \\
(0.1219)\end{array}$ & $\begin{array}{c}-0.1730 \\
(0.1199)\end{array}$ & $\begin{array}{l}-0.1673 \\
(0.1242)\end{array}$ & $\begin{array}{l}-0.1791 \\
(0.1241)\end{array}$ \\
\hline Observations & 256 & 256 & 256 & 256 & 256 \\
\hline Adjusted R-squared & 0.063 & 0.093 & 0.125 & 0.059 & 0.065 \\
\hline
\end{tabular}

Notes: The Table reports OLS estimates. Standard errors (reported in parentheses) are corrected for heteroskedasticity and allowing for clustering at the match level. The symbols $* * *, * *, *$ indicate that coefficients are statistically significant, respectively, at the 1,5 , and 10 percent level.

\section{Concluding Remarks}

Whereas the home advantage in soccer is a well-documented phenomenon, there is little evidence on which factor plays the major role in its determination. The main mechanisms identified in the literature appear to be crowd support, familiarity with the stadium and travel fatigue, but it remains great uncertainty on whether and to what extent each of these factors contributes to the home advantage.

In this paper, in order to identify the role played by crowd support and thus to disentangle this effect from the other mechanisms contributing to the home advantage, we have focused on same-stadium derbies: these matches allow us to neutralize any factor related to players' familiarity with the stadium and to travel fatigue in influencing team performance, given that these factors are identical for the two competing teams. The only remaining difference in derbies is the proportion of supporters for the two teams, which is largely in favor of the home team, because of season ticket holders and seat reservations for home supporters.

We have found that the crowd support has a strong and significant impact on team performance in derbies: the home team scores about 0.45 goals more than the visiting team and the probability of winning of the former is about 13 percentage points higher. This impact is slightly lower in magnitude that the home advantage emerging in normal matches, suggesting that a large part of the home advantage is due to the crowd support, although a significant role is also played by players' familiarity with the stadium and travel fatigue of the visiting team.

Finally, building a measure of referee's decisions in favor of two home team, we have tentatively investigated if the support of the crowd affects the outcome of the match mainly through its impact on the referee or through the encouragement of home players. Our results suggest that both these factors are at work: referees are more prone to favor the home team, but taking as constant the referees' influence on the outcome we find that the home team tends to perform better thanks to the direct support of the crowd. 


\section{References}

Agnew, G., and Carron, A. (1994). Crowd effects and the home advantage. International Journal of Sport Psychology, 25(1), 53-62.

Barnett, V., and Hilditch, S. (1993). The effect of an artificial pitch surface on home team performance in football (soccer). Journal of the Royal Statistical Society. Series A (Statistics in Society), 39-50.

Brown TD, Van Raalte JL, Brewer BW et al. (2002). World cup soccer home advantage. Journal of SportBehavior, 25(2), 134-144.

Carron, A., Loughhead, T. Bray, S. (2005), "The home advantage in sport competitions: Courneya and Carron's (1992) conceptual framework a decade later", Journal of Sports Sciences, 23:4, 395-407.

Clarke, S., and Norman, J. (1995). Home ground advantage of individual clubs in English soccer. The Statistician, 44(4), 509-521.

Courneya, K.S. and Carron, A. (1992). The home advantage in sport competitions: A literature review. Journal of Sport and Exercise Psychology, 14, 13-27.

Dawson, P. and Dobson, S. (2010). The influence of social pressure and nationality on individual decisions: Evidence from the behaviour of referees. Journal of Economic Psychology, 31, 181-191.

Dohmen, T. J. (2008). The influence of social forces: Evidence from the behavior of football referees. Economic Inquiry, 46, 411- 424.

Garicano, L., Palacios-Huerta, I. and Prendergast, C. (2005). Favoritism under social pressure. Review of Economics and Statistics, 87, 208-16.

Loughead, T., Carron, A., Bray, S., and Kim, A. (2003), "Facility familiarity and the home advantage in professional sports", International Journal of Sport and Exercise Psychology, 1(3), 264-274.

Garicano, L., and Palacios-Huerta, I. (2005). Sabotage in tournaments: Making the beautiful game a bit less beautiful. Centre for Economic Policy Research.

Goumas C. (2014). Home advantage in Australian soccer. Journal of Science and Medicine in Sport, 17(1), 119-123.

Neave, N., and Wolfson, S. (2003). Testosterone, territoriality, and the home advantage. Physiology and Behavior, 78(2), 269-275.

Nevill, A., Balmer, N., and Williams, A. (2002). The influence of crowd noise and experience upon refereeing decisions in football. Psychology of Sport Exercise, 3(4), 261-272.

Nevill, A.M. and Holder, R.L. (1999). Home advantage in sport: An overview of studies on the advantage of playing at home. Sports Med, 4, 221-236.

Nichols, M. (2014). The impact of visiting team travel on game outcome and biases in NFL betting markets". Journal of Sports Economics, 15(1) 78-96.

Oberhofer, H., Philippovich, T., Winner, H. (2010). Distance matters in away games: Evidence from German football league. Journal of Economic Psychology, 31, 200-211.

Page, K. and Page, L. (2010). Alone against the crowd: Individual differences in referees' ability to cope under pressure". Journal of Economic Psychology, 31, 192-199.

Pollard R. (1986). Home advantage in soccer: a retrospective analysis. Journal of Sports Sciences, 4(3), 237248.

Pollard, R. (1986). Home advantage in soccer: A retrospective analysis. Journal of Sports Sciences, 4(3), 237-248.

Pollard, R. (2002). Evidence of a reduced home advantage when a team moves to a new stadium. Journal of Sports Sciences, 20, 969-973.

Pollard, R. (2006). Worldwide regional variations in home advantage in association football. Journal of Sports Sciences, 24(3), 231-240.

Pollard, R. and Pollard, G. (2005). Home advantage in soccer. A review of its existence and causes. International Journal of Soccer and Science Journal, 3(1), 28-38.

Salminen, S. (1993). The effect of the audience on the home advantage. Perceptual and Motor Skills, 76, $1123-1128$.

Scoppa, V. (2008). Are subjective evaluations biased by social factors or connections? An econometric analysis of soccer referee decisions. Empirical Economics, 1, 123-140. 
Strauss, B. (2002). The impact of supportive spectator behavior on performance in team sports. International Journal of Sport Psychology, 33, 372 - 390.

Sutter, M., and Kocher, M. (2004). Favoritism of agents - The case of referees' home bias. Journal of Economic Psychology, 25(4), 461-469.

Ven, N. van de (2011), "Supporters are not necessary for the home advantage: Evidence from same-stadium derbies and games without an audience", Journal of Applied Social Psychology, 41(12), 2785-2792. 